\title{
Mini-Review
}

Fetal Diagnosis and Therapy
Fetal Diagn Ther 2012;31:201-209

DOI: $\underline{10.1159 / 000338146}$
Received: January 13, 2012

Accepted after revision: March 14, 2012

Published online: April 25, 2012

\section{Fetal and Maternal Analgesia/Anesthesia for Fetal Procedures}

\author{
Marc Van de Velde Frederik De Buck \\ Department of Anesthesiology, University Hospitals Gasthuisberg, Katholieke Universiteit Leuven, Leuven, Belgium
}

\section{Key Words}

Fetal surgery · Fetal pain · Fetal anesthesia • Obstetric anesthesia

\begin{abstract}
For many prenatally diagnosed conditions, treatment is possible before birth. These fetal procedures can range from minimal invasive punctions to full open fetal surgery. Providing anesthesia for these procedures is a challenge, where care has to be taken for both mother and fetus. There are specific physiologic changes that occur with pregnancy that have an impact on the anesthetic management of the mother. When providing maternal anesthesia, there is also an impact on the fetus, with concerns for potential negative side effects of the anesthetic regimen used. The question whether the fetus is capable of feeling pain is difficult to answer, but there are indications that nociceptive stimuli have a physiologic reaction. This nociceptive stimulation of the fetus also has the potential for longer-term effects, so there is a need for fetal analgesic treatment. The extent to which a fetus is influenced by the maternal anesthesia depends on the type of anesthesia, with different needs for extra fetal anesthesia or analgesia. When providing fetal anesthesia, the potential negative consequences have to be balanced against the intended benefits of blocking the physiologic fetal responses to nociceptive stimulation.
\end{abstract}

Copyright $\odot 2012$ S. Karger AG, Basel

\section{KARGER}

Fax +4161306 1234

E-Mail karger@karger.ch

www.karger.com
C 2012 S. Karger AG, Basel

$1015-3837 / 12 / 0314-0201 \$ 38.00 / 0$

Accessible online at:

www.karger.com/fdt

\section{Introduction}

At present, the unborn child is increasingly being treated as a patient in its own right. Thanks to advances in high resolution ultrasound and other diagnostic techniques, an increasing number of conditions are diagnosed early in gestation and insight into their pathophysiology has also been gained. Some of these conditions are life-threatening in utero or result in irreversible organ damage and may benefit from prenatal surgical intervention.

From being an experimental technique, only performed by a few audacious surgeons and obstetricians, fetal surgery has evolved into a more mainstream form of treatment for some prenatally diagnosed fetal or placental conditions [1]. Depending on the pathology, different approaches for fetal interventions are possible, with different levels of invasiveness. Providing anesthesia for procedures ranging from complex open surgery to minimally invasive ultrasound-guided procedures $[2,3]$ can be challenging.

Open fetal surgery, for example, is performed in cases of severe myelomeningocele, where prenatal closure gives better results in survival and neurologic functioning than postnatal repair $[4,5]$. Also large sacral teratomas and cystic lung lesions can be resected if there is a severe impact on the further viability of the fetus [3]. 
Endoscopic surgery on the fetus, for example, is performed in the case of congenital diaphragmatic hernia, where growth of the hypoplastic lung is induced and accelerated by plugging the fetal trachea with a balloon, the FETO procedure $[6,7]$. Other endoscopic procedures on the fetus are vesicoamniotic shunts for lower urinary tract occlusion or other shunting procedures, such as for pleural effusions [2].

Endoscopic surgery on the placenta and membranes is performed for twin-to-twin transfusion syndrome, where laser ablation of connecting vessels gives better results than expectant management with serial amniodrainages [8-10]. Other abnormalities of monochorionic twins sometimes warrant a selective reduction of the pregnancy to protect the viable twin. In these cases, a selective feticide can be performed with an endoscopic laser, bipolar or radiofrequency coagulation of one cord [11, 12].

Where other fetal procedures are performed in the second or early third trimester of pregnancy, the ex utero intrapartum treatment (EXIT) procedure is performed near term, often with the aim of securing the fetal airways before birth, immediately before delivering the fetus through a cesarian section. While the fetus is still oxygenated on the placental circulation, the airways can be secured or an extracorporeal membrane oxygenator can be connected before the placental cord is clamped $[13,14]$.

In this review, specific aspects of anesthesia for fetal surgical procedures are described, looking from both the maternal and the fetal point of view.

\section{Maternal Anesthetic Aspects of Fetal Surgery}

\section{Physiologic Changes of Pregnancy and Their Impact}

on Anesthetic Management [15]

Respiratory System

Airway management becomes increasingly demanding when gestation progresses because of increased body weight, short neck, enlarged breasts, nasopharyngeal edema and capillary engorgement and the increased susceptibility of the nasopharynx to be traumatized $[16,17]$. Oxygen consumption is increased as well as alveolar ventilation. As a result respiratory alkalosis is present during pregnancy. Functional residual capacity is decreased by approximately $20 \%$ [18].

The pregnant patient is more prone to hypoxia because of decreased functional residual capacity and increased oxygen consumption [19]. Careful denitrogenation prior to the induction of general anesthesia is therefore recommended. The physiologic mild respiratory alkalosis should be maintained during artificial ventilation since both hypercarbia or very low levels of carbon dioxide can compromise uteroplacental perfusion.

\section{Cardiovascular System}

Plasma volume increases by approximately $45 \%$. A state of hypercoagulability develops. Cardiac output, stroke volume and heart rate are increased. Myocardial contractility is unchanged and systemic vascular resistance is decreased [18]. The enlarging uterus causes compression of the inferior vena cava and the aorta resulting in the so-called supine hypotensive syndrome. Many conditions that are treated by fetal surgery also present with polyhydramnios [20], increasing the risk for caval compression, so prevention by use of a left lateral tilt position is important.

Pregnant patients are more prone to thromboembolic complications and adequate prophylactic measures should be taken including prophylactic administration of low-molecular-weight heparins $[18,21]$.

\section{Gastrointestinal Changes}

The enlarging uterus causes increased intragastric pressure. Combined with a decreased lower esophageal sphincter tone and increased gastric acid secretion, the chance of gastric regurgitation is increased. Acid aspiration prophylaxis (in our institution a combination of an $\mathrm{H}_{2}$ receptor antagonist, sodium citrate orally $30 \mathrm{ml} 0.3 \mathrm{M}$ and metoclopramide) is therefore recommended to reduce gastric secretion and increase gastric $\mathrm{pH}$ [22].

\section{Central Nervous System}

Central nervous system depression occurs secondary to increased progesterone levels. The epidural space capacity is reduced due to engorgement of the epidural venous plexus $[23,24]$. Pregnancy is associated with a decreased minimal alveolar concentration of volatile anesthetics [25] and a higher sensitivity to local anesthetics [23].

The combined changes in physiology during pregnancy predispose the pregnant patient to higher risks when general anesthesia is performed, making local or regional anesthesia a safer option when possible [26].

\section{Anesthetic Techniques for Fetal Surgical Interventions} (table 1)

General and regional anesthesia can be performed, depending on the type of procedure [15]. 
Table 1. Maternal and fetal anesthetic management

\begin{tabular}{|c|c|c|}
\hline Open surgery & $\begin{array}{l}\text { general anesthesia with or without epidural } \\
\text { anesthesia }\end{array}$ & $\begin{array}{l}\text { fetus is anesthetized through placental passage, additional } \\
\text { anesthesia can be obtained by fetal (i.m. or cord) opioids } \\
\text { (e.g. fentanyl } 10 \mu \mathrm{g} / \mathrm{kg} \text { ) and muscle relaxants } \\
\text { (e.g. pancuronium } 0.3 \mathrm{mg} / \mathrm{kg} \text { ) }\end{array}$ \\
\hline $\begin{array}{l}\text { Fetoscopic fetal } \\
\text { surgery }\end{array}$ & $\begin{array}{l}\text { local anesthesia or regional anesthesia (spinal, } \\
\text { epidural of combined spinal epidural)* }\end{array}$ & $\begin{array}{l}\text { fetal (i.m. or cord) opioids (e.g. fentanyl } 10 \mu \mathrm{g} / \mathrm{kg} \text { ) and } \\
\text { muscle relaxants (e.g. pancuronium } 0.3 \mathrm{mg} / \mathrm{kg} \text { ), or maternal } \\
\text { i.v. remifentanil } 0.1-0.2 \mu \mathrm{g} / \mathrm{kg} / \mathrm{min}\end{array}$ \\
\hline $\begin{array}{l}\text { Fetoscopic surgery on } \\
\text { placenta and cord }\end{array}$ & $\begin{array}{l}\text { local anesthesia or regional anesthesia (spinal, } \\
\text { epidural of combined spinal epidural)* }\end{array}$ & maternal i.v. remifentanil $0.1-0.2 \mu \mathrm{g} / \mathrm{kg} / \mathrm{min}$ \\
\hline $\begin{array}{l}\text { Late termination of } \\
\text { pregnancy }\end{array}$ & $\begin{array}{l}\text { local anesthesia or regional anesthesia } \\
\text { (if labor is induced and patient requests } \\
\text { regional analgesia for labor; epidural or } \\
\text { combined spinal epidural) }\end{array}$ & $\begin{array}{l}\text { fetal (i.m. or cord) opioids (e.g. fentanyl } 10 \mu \mathrm{g} / \mathrm{kg} \text { ), followed } \\
\text { by drugs to perform feticide (potassium or lidocaine) }\end{array}$ \\
\hline
\end{tabular}

* Most fetoscopic procedures are very well tolerated under local maternal anesthesia, regional anesthesia is chosen for complex procedures or when a backup cesarian section could be necessary.

\section{Open Fetal Surgery}

A general anesthetic is usually needed for the maternal laparotomy and hysterotomy [20]. After a rapid sequence induction, when volatile anesthetics are used to maintain anesthesia, at least $2 \mathrm{MAC}$ is used for profound uterine relaxation. Intravenous anesthesia can be supplemented with volatiles for uterine relaxation [27]. If needed, intravenous nitroglycerin can also be used for short-lasting uterine relaxation $[28,29]$. The use of high concentrations of volatiles and nitroglycerin often necessitates vasopressor support for adequate uteroplacental perfusion. Invasive monitoring of the arterial blood pressure is required, and a central venous line is often placed. There is a risk of postoperative pulmonary edema, so fluids should be restricted $[27,30]$.

Adequate postoperative pain control is necessary for the prevention of uterine contractions and premature delivery, for example with epidural patient-controlled analgesia. Circulating oxytocin concentrations were lower in an animal model of open fetal surgery when adequate postoperative analgesia was provided with morphine infusions [31]. Prophylactic tocolysis is started preoperatively with rectal indomethacin $50 \mathrm{mg}$, and postoperative tocolysis can be provided, together with adequate analgesia, by a magnesium sulphate infusion
[3]. Careful monitoring of the recovery of the neuromuscular function is required, since magnesium sulphate potentiates nondepolarizing neuromuscular blockers. Other tocolytic drugs that can be used postoperatively are intravenous atosiban, oral nifedipine or subcutaneous terbutaline. In addition to fluid overload, some tocolytic regimens can also contribute to the development of pulmonary edema [32].

Frequent complications after open fetal surgery are pulmonary edema, premature labor, amniotic fluid leak and fetal demise. Sometimes admission to ICU may be necessary [30].

Because of the risks for major maternal and fetal morbidity, many open fetal procedures are attempted to perform less invasively, with the development of new fetoscopic techniques [1].

\section{Minimally Invasive Fetal Surgery}

Minimally invasive procedures include ultrasoundguided needling for fetal blood sampling, intrauterine transfusion, selective feticide, radiofrequency ablation of a nonviable twin [11] or fetal cardiac puncture for laser atrial septostomy [33]. Fetoscopic procedures (intrauterine endoscopic surgery) are performed for laser coagulation of connecting vessels in twin-to-twin transfusion 
syndrome [8], selective cord occlusion [12], fetal endoscopic tracheal balloon occlusion and the subsequent removal of the tracheal balloon [6] or the resection of urethral valves [34].

These procedures are less invasive for the mother, so general anesthesia is not always necessary [30]. Many ultrasound-guided needling procedures can be performed using local anesthesia of the maternal abdominal wall alone [35]. For most fetoscopic procedures either a local anesthetic or regional anesthesia such as epidural or combined spinal epidural anesthesia is used [36]. If general anesthesia is necessary, the same type of anesthesia as for open fetal procedures can be used. However, the concentrations of volatile anesthetics do not need to be as high because the trauma to the uterus and the uterine activity is less [37].

When using a local or regional anesthesia technique, the fetus does not receive any anesthesia or analgesia [36]. When the mother is lightly sedated by an intravenous infusion of remifentanil, transplacental passage also provides immobilization of the fetus [38].

\section{EXIT Procedures}

These procedures are mostly performed with a general anesthesia comparable to open fetal surgery, with high concentrations of volatile anesthetics to ensure uterine relaxation [39]. Uterine relaxation is needed to prevent placental separation and to preserve the uteroplacental circulation. Since the uteroplacental circulation is dependent on maternal hemodynamic stability, inotropes, vasopressors or fluids may be used for treatment of maternal hypotension. Invasive monitoring is highly recommended for the prevention of maternal hypotension, with decreased uteroplacental perfusion $[40$, 41].

When a general anesthetic is not possible (for example, for patients at risk of malignant hyperthermia or with a known difficult airway [42]), a regional technique, CSE or continuous spinal anesthesia, can be used with intravenous nitroglycerin to provide a rapidly reversible, profound uterine relaxation $[28,29,43]$.

There is a risk of major intraoperative and postoperative maternal blood loss particularly during lengthy procedures. Postoperative blood loss is associated with uterine atony, possibly due to the prolonged effects of tocolytics $[41,44]$.

\section{Fetal Anesthetic Aspects of Fetal Surgery}

\section{Fetal Effects of Anesthesia}

Teratogenic Effects

Are anesthetic agents teratogenic? Several factors determine whether a drug is teratogenic or not. Especially the timing of exposure to the drug and the dose of the anesthetic drug used seem to be important determining factors. Anesthetic agents, at clinically relevant concentrations, have potentially harmful effects on cells, including decreased cell motility, prolongation of DNA synthesis and inhibition of cell cleavage [45]. Despite these concerns, no data are available to link teratogenicity with these agents in humans. Prospective, randomized trials are impractical and often considered unethical. Research has focussed therefore on animal data, epidemiological surveys and reports of pregnancy outcome in women who have undergone surgery during pregnancy. Opioids seem to be devoid of teratogenic effects in both animal and human studies [46, 47]. Benzodiazepines became controversial after reports of an association between cleft palate and maternal diazepam ingestion during the first trimester [48]. However, subsequent prospective reports failed to confirm this association. A single dose of benzodiazepines for preoperative anxiolysis can safely be used $[49,50]$. Teratogenesis has also not been associated with the use of any commonly used induction agents [51]. Clinically relevant doses of commonly used muscle relaxants are also safe [52]. No evidence supports teratogenicity associated with local anesthetics used in clinically relevant doses [53]. If normal homeostasis is maintained, also halogenated agents also seem to be safe. Nitrous oxide is a weak teratogen used in animal studies and cell cultures, but this was not demonstrated in clinical use in pregnant patients. Concerns about teratogenicity of nitrous oxide are mainly focussed on long-term occupational exposure to low concentrations [54].

\section{Effects of Anesthetic Drugs on Brain Development}

[55]

Since an initial report in 2003 about possible negative effects of anesthesia administered early in life on brain development, much concern and debate have risen over the safety of anesthesia in young children. In one publication [56], neonatal rats were subjected to a prolonged period of anesthesia, leading to a deficit in spatial recognition tasks at later ages. These findings were later reproduced also in other species, including primates [57].

The pathophysiologic basis for these effects on brain development is partially attributed to anesthesia-related 
neurodegeneration, with an increase in neuroapoptosis above the normal developmental apoptosis which occurs during normal brain development [58]. Other contributing pathophysiologic pathways are the effects of anesthesia on synaptogenesis, with reduced dendritic spine density after propofol exposure in rats [59] and decreased neurogenesis with effects on neural plasticity [60].

Although the evidence for impaired neurodevelopment after early anesthetic exposure is corroborated by different animal studies, it is still unclear whether this has any clinical implications for anesthesia in human children. The effects of surgery with anesthesia in early childhood are studied with large cohort studies, but either the studies were unable to differentiate between the effects of anesthesia and the effects of surgery and the associated pathology [61], or they were unable to demonstrate an effect of anesthesia on the incidence of learning disabilities [62]. More research is ongoing in this rapidly evolving field, and no definite conclusions are yet available.

Indirect Effects of Anesthetic Drugs on the Fetus

Intrauterine asphyxia is the most important fetal risk associated with maternal surgery and anesthesia during pregnancy. To maintain normal fetal oxygenation, maintenance of normal maternal oxygenation and uteroplacental perfusion are critical.

Transient mild decreases in maternal oxygenation are well tolerated by the fetus, because of the high affinity of fetal hemoglobin for oxygen. Severe, prolonged maternal hypoxemia results in fetal hypoxia or even fetal death. Any anesthetic complication that causes profound maternal hypoxemia is a potential threat to the fetus [63].

Both maternal hypercapnia and maternal hyperventilation can cause fetal problems. Hypercapnia results in fetal acidosis [64]. Maternal hyperventilation adversely affects fetal oxygenation: umbilical artery vasoconstriction, leftward shift of the oxyhemoglobin dissociation curve and reduction in maternal cardiac output as a result of positive pressure ventilation are all consequences of maternal hyperventilation.

Maternal hypotension from any cause can jeopardize fetal well-being by reducing uteroplacental perfusion. Prompt treatment using intravenous fluids, careful positioning with a wedge to avoid aorto-caval compression, reducing the depth of anesthesia or vasopressors is mandatory. Recently, the alpha-adrenergic agent phenylephrine has been reappraised as the agent of choice for treating maternal hypotension [63].

Fetal and Maternal Analgesia/Anesthesia for Fetal Procedures
Direct Fetal Circulatory Effects of Anesthetic Agents

The volatile anesthetic agents have direct depressant effects on the fetal cardiovascular system. Especially when high concentrations of volatile agents are used fetal acidosis might occur. Low-to-moderate concentrations $(<1.5 \mathrm{MAC})$ seem to be devoid of fetal effects in pregnant ewes [65]. However, especially during open fetal surgery, high concentrations are used regularly to provide uterine relaxation. This might be detrimental for the fetus, especially if surgery is prolonged.

Systemic drugs such as opioids and induction agents produce fetal anesthesia, reduce the fetal heart rate variability but do not result in fetal acidosis as long as maternal hemodynamics remain stable [66]. Maternally administered muscle relaxants have little or no effects on the fetus because of their low placental passage [52].

\section{Evidence that the Fetus Experiences Pain or Responds} to Noxious Stimuli

The question of whether a fetus experiences pain is an immense challenge. The issue demands consideration of the physical and psychological basis of being and the relation between the two [67]. There is no objective measurement of 'pain'; it is a subjective experience. The fetus is unable to tell us if it feels pain, so other evidence must be used to decide whether the fetus feels pain. Because of the obvious difficulties in studying fetal behavior, activation of the hypothalamo-pituitary-adrenal (HPA) axis (the 'stress response') has been proposed as a surrogate indicator of fetal pain [68]. This has limitations: stress responses do not necessarily signify pain (for example, during exercise), and stress responses do not involve the cortex. However, the converse is the null hypothesis, i.e. in the absence of a stress response the fetus is unlikely to experience pain.

\section{Hormonal Responses}

Due largely to the research work of Anand [69], we are aware that preterm neonates have hormonal stress responses following invasive interventions. These hormonal responses can be prevented by analgesia. As a result, similar studies were performed in the unborn child. Activation of the fetal HPA axis stress response can be assessed by measuring stress hormones such as noradrenaline, cortisol, $\beta$-endorphin and corticotrophin. Fisk and colleagues $[70,71]$ studied samples obtained prior to and following in utero fetal blood transfusion and compared the levels of these hormones before transfusion (immediately after access to the fetal circulation was established) with the levels at the end of transfusion (just before the 
needle was removed). Fetal plasma was obtained during fetal blood sampling for intrauterine transfusion either by needling the fetal intrahepatic vein or by needling the placental cord insertion. Since the placental cord insertion is not innervated, no stress response was observed, whereas in the intrahepatic vein-transfused fetus a significant increase in stress hormones was recorded. The fetal HPA system is functional from at least the beginning of the second trimester.

\section{Hemodynamic Responses}

It is well known from animal studies that the fetus in late gestation has a remarkable capacity to redistribute its blood flow in response to acute stressors (hypoxemia, hemorrhage) to protect its more vital organs, such as the brain and myocardium, and this at the expense of other organs such as gut, kidneys and the extremities. Similarly, some chronic stressors, such as sustained hypoxemia or prolonged reductions in uterine blood flow, were also associated with increased brain blood flow. In the human fetus, Doppler ultrasonography studies have shown an association between chronic hypoxemia of intrauterine growth restriction and redistribution of blood flow [72]. Fisk et al. [71] demonstrated that acute painful stimuli (transgression of the fetal abdominal wall during in utero transfusion) were associated with a significant hemodynamic response in the fetus. This hemodynamic stress response is consistent with the redistribution of blood supply to the brain.

\section{Anatomical Considerations [73]}

To experience pain an intact system of pain transmission from the peripheral receptor to the cerebral cortex must be available. Peripheral receptors develop from the seventh gestational week. From 20 weeks' gestation peripheral receptors are present on the whole body. From 13 weeks' gestation the afferent system located in the substantia gelatinosa of the dorsal horn of the spinal cord starts developing. Development of afferent fibers connecting peripheral receptors with the dorsal horn starts at 8 weeks' gestation. Spinothalamic connections start to develop from 14 weeks' and are complete at 20 weeks' gestation, whilst thalamocortical connections are present from 17 weeks' and completely developed at 26-30 weeks' gestation. From 16 weeks' gestation pain transmission from a peripheral receptor to the cortex is possible and completely developed from 26 weeks' gestation. It is important to note that serotonine-releasing inhibitory descending pain fibers only develop following birth [74].

\section{The Need for Adequate Fetal Anesthesia}

Whether a fetus is capable of experiencing pain as a conscious and emotional feeling remains unclear and is subject to great debate [67], but we cannot deny that the fetal nervous system mounts protective responses to tissue injury. A physiological fetal reaction to painful stimuli occurs from between 16 and 24 weeks' gestation on.

The fetal nervous system mounts protective responses to tissue injury. The evidences for early exposure to noxious stimuli resulting in adverse effects on future neural development are increasing. This means noxious stimulation may not need to penetrate consciousness in order to substantially alter the course of sensory development. Ruda [75] reported localized inflammation during the neonatal period permanently alters neuronal circuits that process pain in the spinal cord. Preterm neonates who had experienced 4 weeks of NICU (neonatal intensive care unit) therapy manifested decreased behavioral responses and increased cardiovascular responses to the pain of a heel prick as compared to neonates born at 32 weeks. Differences in these response patterns were strongly correlated with the number of invasive procedures experienced since birth, rather than other clinical factors (such as age, Apgar score, birth weight, severity of illness or weight at 32 weeks postconception) [76]. These data suggest that repetitive pain and stress may alter the neurologic substrate associated with pain, leading to altered neurobehavioral responses from subsequent pain in preterm neonates.

According to Anand et al. [77], repetitive pain in neonatal rat pups may lead to an altered development of the pain system associated with decreased pain thresholds during development. Increased plasticity of the neonatal brain may allow these and other changes in brain development to increase their vulnerability to stress disorders and anxiety-mediated adult behavior [78]. Similar behavioral changes have been observed during later childhood of ex-preterm neonates who were exposed to prolonged periods of neonatal intensive care [69]. Recent studies suggest that although early painful memories are not accessible to conscious recall, they may be encoded in 'procedural memory' and lead to abnormal behavioral patterns or altered sensory processing in later life. Taddio et al. [79] demonstrated that children undergoing a ritual circumcision immediately after birth (without pain relief) react much more vigorously to painful stimuli later in life such as vaccination at 2 months of age.

It is becoming increasingly clear that experiences of pain will be 'remembered' by the developing nervous system, perhaps for the entire life of the individual. These 
findings should focus the attention of clinicians on the long-term impact of early painful experiences, and highlight the urgent need for developing therapeutic strategies for the management of neonatal and fetal pain.

\section{Fetal Anesthetic Techniques (table 1) [35]}

Fetal anesthesia can be necessary for prevention of fetal movements and it can also help to reduce the fetal physiologic responses to noxious stimulation, possibly reducing any long-term consequences.

Fisk et al. [71] showed that direct administration of 10 $\mu \mathrm{g} / \mathrm{kg}$ fentanyl intravenously to the fetus blunts the fetal stress response to intrauterine needling. The magnitude of the $\beta$-endorphin and cortisol response was halved, and the cerebral Doppler response was ablated.

\section{Open Fetal Surgery and EXIT Procedures}

During open fetal surgery and EXIT procedures under maternal general anesthesia, inhalational agents are considered to provide adequate fetal anesthesia and produce uterine relaxation essential for successful surgery. So, additional analgesia for the fetus is unnecessary. Direct fetal administration of fentanyl and muscle relaxation is reserved for cases where the fetus moves during the procedure. Also when an EXIT procedure is performed under maternal regional anesthesia, specific fetal anesthesia is needed to avoid fetal movements.

Fetal analgesia and muscle relaxation can be given intramuscularly, for example fentanyl $10 \mu \mathrm{g} / \mathrm{kg}$ and pancuronium or vecuronium $0.2 \mathrm{mg} / \mathrm{kg}$. Fetal resuscitation drugs should also be ready for the surgeon to administer if needed, for example atropine $0.02 \mathrm{mg} / \mathrm{kg}$ and adrenaline $1 \mu \mathrm{g} / \mathrm{kg}$ [35].

Fetal monitoring during the procedure is possible with fetal pulse oximetry and near-infrared spectroscopy for fetal oxygenation monitoring, fetal echocardiography, a fetal scalp electrode for heart rate monitoring and fetal umbilical blood sampling for fetal blood gases and acid base status [80-82].

Fetal transfusion blood should be available; blood group $\mathrm{O}$ rhesus negative leukocyte-free blood is used in aliquots of $5 \mathrm{ml} / \mathrm{kg}$.

\section{Minimally Invasive Fetal Surgery}

Some endoscopic procedures performed directly on the fetus, such as tracheal occlusion or repair of meningomyelocele, are usually performed under maternal local or regional anesthesia. Since these procedures do not require maternal general anesthesia, additional fetal anesthesia is desired and is usually done by direct administra- tion of opioids and muscle relaxants to the fetus. Injection of these drugs in the umbilical cord or intramuscularly into the fetus are two possible routes of administration. At our institution it is also customary to add atropine $(0.02-0.03 \mathrm{mg} / \mathrm{kg})$ to the mixture directly administered to the fetus.

The term obstetric endoscopy was proposed for procedures on the placenta, the umbilical cord and fetal membranes. Obstetric endoscopic procedures do not require direct contact with the fetus. The risks of maternal (and consequently fetal) general anesthesia are unlikely to be justified by the degree of stress response inflicted on the fetus. However, immobilization of the fetus is required to prevent accidental fetal movements complicating these procedures. In these instances fetal immobilization is possible using maternally administered sedative drugs such as diazepam. However, we recently determined that remifentanil in doses as low as $0.1 \mu \mathrm{g} / \mathrm{kg} / \mathrm{min}$ produces effective maternal sedation and fetal immobilization during these procedures and that remifentanil compared favorably to diazepam to produce fetal immobility [38].

Some authors even suggest providing analgesia to the unborn child in very specific situations such as late pregnancy termination, painful fetal conditions and during vaginal delivery, especially during instrumental vaginal delivery. At the moment the potential side effects of analgesia outweigh the theoretical advantages and we cannot advise on its routine use in these specific situations. Only during late pregnancy termination would we advise to provide fetal analgesia prior to initiation of termination.

\section{Conclusion}

Anesthesia for pregnant patients undergoing surgery is demanding because of the increased risks of anesthesia associated with pregnancy. Hemodynamic stability is the cornerstone of good anesthetic management in order to provide a safe environment for the unborn child. Evidence is increasing that from the second trimester onwards, the fetus reacts to painful stimuli and that these painful interventions may cause long-term effects. It is therefore recommended to provide adequate pain relief during potentially painful procedures during in utero life. 


\section{References}

$>1$ Deprest JA, Flake AW, Gratacos E, et al: The 17 Boutonnet M, Faitot V, Keïta H: Airway making of fetal surgery. Prenat Diagn 2010; 30:653-667.

$>2$ Deprest JA, Devlieger R, Srisupundit K, et al: Fetal surgery is a clinical reality. Semin Fetal Neonatal Med 2010;15:58-67.

3 Adzick NS: Open fetal surgery for lifethreatening fetal anomalies. Semin Fetal Neonatal Med 2010;15:1-8.

-4 Adzick NS, Thom EA, Spong CY, et al: A randomized trial of prenatal versus postnatal repair of myelomeningocele. N Engl J Med 2011;364:993-1004.

$\checkmark 5$ Clayton DB, Tanaka ST, Trusler L, et al: Long-term urological impact of fetal myelomeningocele closure. J Urol 2011;186:15811585.

-6 Ruano R, Duarte SA, Pimenta EJ de A, et al: Comparison between fetal endoscopic tracheal occlusion using a $1.0-\mathrm{mm}$ fetoscope and prenatal expectant management in severe congenital diaphragmatic hernia. Fetal Diagn Ther 2011;29:64-70.

7 Deprest J, Nicolaides K, Doné E, et al: Technical aspects of fetal endoscopic tracheal occlusion for congenital diaphragmatic hernia. J Pediatr Surg 2011;46:22-32.

$>8$ Chalouhi GE, Essaoui M, Stirnemann J, et al: Laser therapy for twin-to-twin transfusion syndrome (TTTS). Prenat Diagn 2011;31: 637-646.

$>9$ Lombardo ML, Watson-Smith DJ, Muratore CS, Carr SR, O’Brien BM, Luks FI: Laser ablation of placental vessels in twin-to-twin transfusion syndrome: a paradigm for endoscopic fetal surgery. J Laparoendosc Adv Surg Tech A 2011;21:869-872.

$>10$ Lewi L, Gucciardo L, Van Mieghem T, et al: Monochorionic diamniotic twin pregnancies: natural history and risk stratification. Fetal Diagn Ther 2010;27:121-133.

-11 Paramasivam G, Wimalasundera R, Wiechec M, Zhang E, Saeed F, Kumar S: Radiofrequency ablation for selective reduction in complex monochorionic pregnancies. BJOG 2010;117:1294-1298.

$>12$ Hecher K, Lewi L, Gratacos E, Huber A, Ville Y, Deprest J: Twin reversed arterial perfusion: fetoscopic laser coagulation of placental anastomoses or the umbilical cord. Ultrasound Obstet Gynecol 2006;28:688-691.

-13 Dighe MK, Peterson SE, Dubinsky TJ, Perkins J, Cheng E: EXIT procedure: technique and indications with prenatal imaging parameters for assessment of airway patency. Radiographics 2011;31:511-526.

14 Abraham RJ, Sau A, Maxwell D: A review of the EXIT (Ex utero Intrapartum Treatment) procedure. J Obstet Gynaecol 2010;30:1-5.

15 Cheek TG, Baird E: Anesthesia for nonobstetric surgery: maternal and fetal considerations. Clin Obstet Gynecol 2009;52:535545.

$\$ 16$ Biro P: Difficult intubation in pregnancy. Curr Opin Anaesthesiol 2011;24:249-254. management in obstetrics. Ann Fr Anesth

18 Carlin A, Alfirevic Z: Physiological changes of pregnancy and monitoring. Best Pract Res Clin Obstet Gynaecol 2008;22:801-823.

19 Hignett R, Fernando R, McGlennan A, et al: A randomized crossover study to determine the effect of a $30^{\circ}$ head-up versus a supine position on the functional residual capacity of term parturients. Anesth Analg 2011;113: 1098-1102.

20 Deprest JA, Doné E, Van Mieghem T, Gucciardo L: Fetal surgery for anesthesiologists. Curr Opin Anaesthesiol 2008;21:298-307.

21 Hui C, Lili M, Libin C, et al: Changes in coagulation and hemodynamics during pregnancy: a prospective longitudinal study of 58 cases. Arch Gynecol Obstet 2011;DOI: 10.1007/s00404-011-2137-x

22 Paranjothy S, Griffiths JD, Broughton HK, Gyte GML, Brown HC, Thomas J: Interventions at caesarean section for reducing the risk of aspiration pneumonitis. Int J Obstet Anesth 2011;20:142-148.

23 Zhan Q, Huang S, Geng G, Xie Y: Comparison of relative potency of intrathecal bupivacaine for motor block in pregnant versus non-pregnant women. Int J Obstet Anesth 2011;20:219-223.

24 Higuchi H, Takagi S, Onuki E, Fujita N, Ozaki M: Distribution of epidural saline upon injection and the epidural volume effect in pregnant women. Anesthesiology 2011;114: 1155-1161.

25 Rosen MA: Management of anesthesia for the pregnant surgical patient. Anesthesiology 1999;91:1159.

26 Rollins M, Lucero J: Overview of anesthetic considerations for Cesarean delivery. Br Med

27 Boat A, Mahmoud M, Michelfelder EC, et al: Supplementing desflurane with intravenous anesthesia reduces fetal cardiac dysfunction during open fetal surgery. Paediatr Anaesth 2010;20:748-756

28 Okutomi T, Saito M, Kuczkowski KM: The use of potent inhalational agents for the exutero intrapartum treatment (exit) procedures: what concentrations? Acta Anaesthesiol Belg 2007;58:97-99.

29 Ioscovich A, Shen O, Sichel J-Y, et al: Remifentanil-nitroglycerin combination as an anesthetic support for ex utero intrapartum treatment (EXIT) procedure. J Clin Anesth 2011;23:142-144

30 Golombeck K, Ball RH, Lee H, et al: Maternal morbidity after maternal-fetal surgery. Am J Obstet Gynecol 2006;194:834-839.

31 Santolaya-Forgas J, Romero R, Mehendale R: The effect of continuous morphine administration on maternal plasma oxytocin concentration and uterine contractions after open fetal surgery. J Matern Fetal Neonatal Med 2006;19:231-238. Reanim 2011;30:651-664. Bull 2012;101:105-125.
32 Ogunyemi D: Risk factors for acute pulmonary edema in preterm delivery. Eur J Obstet Gynecol Reprod Biol 2007;133:143-147.

33 Quintero RA, Huhta J, Suh E, Chmait R, Romero R, Angel J: In utero cardiac fetal surgery: laser atrial septotomy in the treatment of hypoplastic left heart syndrome with intact atrial septum. YMOB 2005;193:14241428.

34 Casella DP, Tomaszewski JJ, Ost MC: Posterior urethral valves: renal failure and prenatal treatment. Int J Nephrol 2012;2012: 351067.

35 Tran KM: Anesthesia for fetal surgery. Semin Fetal Neonatal Med 2010;15:40-45.

>36 Van de Velde M, De Buck F, Van Mieghem T, Gucciardo L, De Koninck P, Deprest J: Fetal anaesthesia: is this necessary for fetoscopic therapy? Fet Matern Med Rev 2010;21:24.

37 Myers LB, Watcha MF: Epidural versus general anesthesia for twin-twin transfusion syndrome requiring fetal surgery. Fetal Diagn Ther 2004;19:286-291.

38 Van de Velde M, Van Schoubroeck D, Lewi LE, et al: Remifentanil for fetal immobilization and maternal sedation during fetoscopic surgery: a randomized, double-blind comparison with diazepam. Anesth Analg 2005; 101:251-258.

-39 Garcia PJ, Olutoye OO, Ivey RT, Olutoye OA Case scenario: anesthesia for maternal-fetal surgery: the Ex Utero Intrapartum Therapy (EXIT) procedure. Anesthesiology 2011;114: 1446-1452.

-40 Lee H, Ryu JW, Kim DY, Lee GY: Anesthetic management of the ex utero intrapartum treatment (EXIT) procedure. A case report. Korean J Anesthesiol 2010;59(suppl):S154S157.

41 Liechty KW: Ex-utero intrapartum therapy. Semin Fetal Neonatal Med 2010;15:34-39.

42 Benonis JG, Habib AS: Ex utero intrapartum treatment procedure in a patient with arthrogryposis multiplex congenita, using continuous spinal anesthesia and intravenous nitroglycerin for uterine relaxation. Int J Obstet Anesth 2008;17:53-56.

43 George RB, Melnick AH, Rose EC, Habib AS Case series: combined spinal epidural anesthesia for Cesarean delivery and ex utero intrapartum treatment procedure. Can J Anaesth 2007;54:218-222.

44 Marwan A, Crombleholme TM: The EXIT procedure: principles, pitfalls, and progress. Semin Pediatr Surg 2006;15:107-115.

45 Stephanova E, Topouzova-Hristova T, Hazarosova R, Moskova V: Halothane-induced alterations in cellular structure and proliferation of A549 cells. Tissue Cell 2008;40: 397-404.

46 Nezvalová-Henriksen K, Spigset O, Nordeng $\mathrm{H}$ : Effects of codeine on pregnancy outcome: results from a large population-based cohort study. Eur J Clin Pharmacol 2011;67:12531261. 
-47 Handal M, Engeland A, Rønning M, Skurtveit S, Furu K: Use of prescribed opioid analgesics and co-medication with benzodiazepines in women before, during, and after pregnancy: a population-based cohort study. Eur J Clin Pharmacol 2011;67:953-960.

-48 Safra MJ, Oakley GP: Association between cleft lip with or without cleft palate and prenatal exposure to diazepam. Lancet 1975;ii:478-480.

-49 Wikner BN, Stiller CO, Bergman U, Asker C, Källén B: Use of benzodiazepines and benzodiazepine receptor agonists during pregnan$c y$ : neonatal outcome and congenital malformations. Pharmacoepidemiol Drug Safety 2007;16:1203-1210.

50 Marinucci L, Balloni S, Carinci F, Locci P, Pezzetti F, Bodo M: Diazepam effects on non-syndromic cleft lip with or without palate: epidemiological studies, clinical findings, genes and extracellular matrix. Expert Opin Drug Saf 2011;10:23-33.

51 Shepard TH, Lemire RJ: Catalog of Teratogenic Agents, ed 11. Baltimore, Johns Hopkins University Press, 2004.

-52 Kampe S, Krombach JW, Diefenbach C: Muscle relaxants. Best Pract Res Clin Anaesthesiol 2003;17:137-146.

53 Fujinaga M: Assessment of teratogenic effects of lidocaine in rat embryos cultured in vitro. Anesthesiology 1998;89:1553-1558.

54 Sanders RD, Weimann J, Maze M: Biologic effects of nitrous oxide. Anesthesiology 2008;109:707-722.

-55 Stratmann G: Neurotoxicity of anesthetic drugs in the developing brain. Anesth Analg 2011;113:1170-1179.

-56 Jevtovic-Todorovic V, Hartman RE, Izumi Y, et al: Early exposure to common anesthetic agents causes widespread neurodegeneration in the developing rat brain and persistent learning deficits. J Neurosci 2003;23: 876-882.

57 Brambrink AM, Evers AS, Avidan MS, et al: Isoflurane-induced neuroapoptosis in the neonatal rhesus macaque brain. Anesthesiology 2010;112:834-841.

58 Loepke AW, Soriano SG: An assessment of the effects of general anesthetics on developing brain structure and neurocognitive function. Anesth Analg 2008;106:1681-1707.
Briner A, Nikonenko I, De Roo M, Dayer A, Muller D, Vutskits L: Developmental Stagedependent persistent impact of propofol anesthesia on dendritic spines in the rat medial prefrontal cortex. Anesthesiology 2011;115: 282-293.

60 Stratmann G, Sall JW, May LDV, et al: Isoflurane differentially affects neurogenesis and long-term neurocognitive function in 60-day-old and 7-day-old rats. Anesthesiology 2009;110:834-848.

61 Wilder RT, Flick RP, Sprung J, et al: Early exposure to anesthesia and learning disabilities in a population-based birth cohort. Anesthesiology 2009;110:796-804.

62 Sprung J, Flick RP, Wilder RT, et al: Anesthesia for cesarean delivery and learning disabilities in a population-based birth cohort. Anesthesiology 2009;111:302-310.

63 Habib AS: A review of the impact of phenylephrine administration on maternal hemodynamics and maternal and neonatal outcomes in women undergoing cesarean delivery under spinal anesthesia. Anesth Analg 2012;114:377-390.

64 O’Rourke N, Kodali B-S: Laparoscopic surgery during pregnancy. Curr Opin Anaesthesiol 2006; 19:254-259.

65 Okutomi T, Whittington RA, Stein DJ, Morishima HO: Comparison of the effects of sevoflurane and isoflurane anesthesia on the maternal-fetal unit in sheep. J Anesth 2009; 23:392-398.

66 Hill D: Remifentanil in obstetrics. Curr Opin Anaesthesiol 2008;21:270-274.

67 Lee SJ, Ralston HJP, Drey EA, Partridge JC, Rosen MA: Fetal pain: a systematic multidisciplinary review of the evidence. JAMA 2005;294:947-954.

68 Anand KJ, Maze M: Fetuses, fentanyl, and the stress response: signals from the beginnings of pain? Anesthesiology 2001;95:823825.

69 Anand KJ: Clinical importance of pain and stress in preterm neonates. Biol Neonate 1998;73:1-9.

70 Smith RP, Gitau R, Glover V, Fisk NM: Pain and stress in the human fetus. Eur J Obstet Gynecol Reprod Biol 2000;92:161-165.
Fisk NM, Gitau R, Teixeira JM, Giannakoulopoulos X, Cameron AD, Glover VA: Effect of direct fetal opioid analgesia on fetal hormonal and hemodynamic stress response to intrauterine needling. Anesthesiology 2001; 95:828-835.

72 Schenone MH, Mari G: The MCA Doppler and its role in the evaluation of fetal anemia and fetal growth restriction. Clin Perinatol 2011;38:83-102.

73 Simons SHP, Tibboel D: Pain perception development and maturation. Semin Fetal Neonatal Med 2006;11:227-231.

74 Fitzgerald M: The development of nociceptive circuits. Nat Rev Neurosci 2005;6:507520.

75 Ruda MA: Altered Nociceptive neuronal circuits after neonatal peripheral inflammation. Science 2000;289:628-630.

76 Anand KJS, Celeste Johnston C, Oberlander TF, Taddio A, Tutag Lehr V, Walco GA: Analgesia and local anesthesia during invasive procedures in the neonate. Clin Ther 2005; 27:844-876.

77 Anand KJ, Coskun V, Thrivikraman KV, Nemeroff CB, Plotsky PM: Long-term behavioral effects of repetitive pain in neonatal rat pups. Physiol Behav 1999;66:627-637.

78 Heim C, Nemeroff CB: The impact of early adverse experiences on brain systems involved in the pathophysiology of anxiety and affective disorders. Biol Psychiatry 1999;46: 1509-1522.

79 Taddio A, Katz J, Ilersich AL, Koren G: Effect of neonatal circumcision on pain response during subsequent routine vaccination. Lancet 1997;349:599-603.

80 Rychik J: Acute cardiovascular effects of fetal surgery in the human. Circulation 2004;110: 1549-1556.

81 Kaneko M, Tokunaga S, Mukai M, et al: Application of a fetal scalp electrode for continuous fetal heart rate monitoring during an ex utero intrapartum treatment. J Pediatr Surg 2011;46:e37-e40.

-82 Reed CA, Baker RS, Lam CT, et al: Application of near-infrared spectroscopy during fetal cardiac surgery. J Surg Res 2011;171:159163. 